\title{
Study of morbidity and mortality profile among low birth weight neonates in sick newborn care unit of a rural medical college and hospital.
}

\author{
Bandyopadhyay 5. ${ }^{1 *}$, Charan Pal A. ${ }^{2}$, Chakraborti S. ${ }^{3}$ \\ DOI: https://doi.org/10.17511/ijpr.2020.i06.07 \\ 1* Sudipta Bandyopadhyay, Senior Resident and former Post Graduate Trainee, Department of Pediatric Medicine, B.S. Medical College, \\ Bankura, West Bengal, India. \\ ${ }^{2}$ Abhay Charan Pal, Associate Professor, Department of Pediatric Medicine, B.S. Medical College, Bankura, West Bengal, India. \\ 3 Snehansu Chakraborti, Professor, Department of Pediatric Medicine, B.S. Medical College, Bankura, West Bengal, India.
}

Introduction: Low birth weight is one of the major health problems in children both in developed and developing countries. Birth asphyxia, neonatal sepsis, hypothermia, hypoglycemia, hyperbilirubinemia, hypocalcemia, MAS, NEC, polycythemia, IVH, meningitis, apnea, BPD, etc are the major risk factors for LBW babies morbidity and mortality. This study was conducted in a tertiary care center to find out morbidity and mortality profiles among low birth weight neonates and shortterm neurodevelopmental outcome. A cross-sectional observational study. 404 low birth weight babies admitted from $1^{\text {st }}$ June 2016 to $31^{\text {st }}$ May 2017. Methods: Both clinical and laboratory data of all the patients were retrieved, compiled, and analyzed. Results: Out of 404 LBW 38 (9.4\%) were ELBW, 134 (33.2\%) were VLBW and rest 232 (57.4\%) were between 1500-<2500gm weight, 88 $(21.8 \%)$ were preterm and IUGR, $219(54.2 \%)$ were male and rest $185(45.8 \%)$ were female. Major cause of morbidity includes hypoglycemia $(17.6 \%)$, RDS (13.1\%), HIE (29.5\%), NEC $(5.7 \%)$, Sepsis $(47.8 \%)$, hyperbilirubinemia (31.9\%), PDA (2.5\%), Apnea $(5.9 \%)$, IVH (1.25\%), congenital anomalies $(5.9 \%)$ etc. Conclusion: In the present series the mortality rate was $(23.5 \%)$ was high. Sepsis, RDS, Birth Asphyxia, and Apnea were the main causes of morbidity and mortality among low birth weight babies. Proper asepsis, judicious use of antibiotics, timely intervention like CPAP, etc reduce the mortality. Proper counseling while discharge regarding feeding, warmth care, asepsis, danger sign and need for follow up plays a pivotal role in the neurodevelopmental outcome.

Keywords: Cross-sectional, India, Low Birth Weight, Morbidity, Mortality, Observational study, Rural based Medical College Hospital

Corresponding Author

Sudipta Bandyopadhyay, Senior Resident and former Post Graduate Trainee, Department of Pediatric Medicine, B.S. Medical College, Bankura, West Bengal, India.

Email: drsudiptabandyopadhyay@gmail.com
How to Cite this Article

To Browse
Bandyopadhyay S, Pal AC, Chakraborti S. Study of morbidity and mortality profile among low birth weight neonates in sick newborn care unit of a rural medical college and hospital.. Pediatric Rev Int J Pediatr Res. 2020;7(6):262-270.

Available From

https://pediatrics.medresearch.in/index.php/ijpr/arti

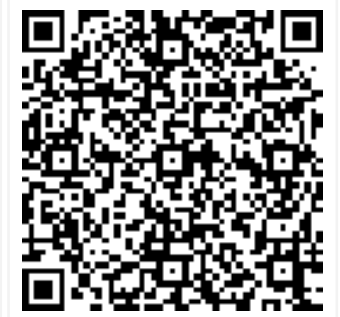
cle/view/613

Manuscript Received 2020-07-21

Conflict of Interest No
Review Round 1 2020-08-04

Funding

Review Round 2
2020-08-17
Ethical Approval
Yes

Review Round 2

Yes
Review Round 3

Plagiarism X-checke $6 \%$
Accepted 2020-08-25

Note

(C) 2020 by Sudipta Bandyopadhyay, Abhay Charan Pal, Snehansu Chakraborti and Published by Siddharth Health Research and Social Welfare Society. This is an Open Access article licensed under a Creative Commons Attribution 4.0 International License https://creativecommons.org/licenses/by/4.0/ unported [CC BY 4.0]. 


\section{Introduction}

BW (LBW) has been defined by the World Health Organization (WHO) as weight at birth of fewer than 2,500 grams (5.5 pounds) in the first hour of delivery [1]. This practical cut-off for international comparison is based on epidemiological observations that infants weighing less than 2,500 gm are approximately 20 times more likely to die than heavier babies. A birthweight below 2,500 gm contributes to a range of poor health outcomes which is more common in developing than developed countries.

LBW is closely associated with fetal and neonatal mortality and morbidity, inhibited growth and cognitive development of children, and increased risks of chronic diseases later in life. Its public health significance may be ascribed to numerous factors - high incidence, association with physical and mental retardation, high risk of perinatal and infant mortality and morbidity, human wastage and suffering, the very cost of special care, and intensive care units and its association with socioeconomic under development. Mortality and morbidity of low birth weight infants are related to their birth weight and gestational age. Quality of care has a significant influence on the survival of these infants. In the industrialized countries, continued improvement in the quality of care has resulted in improvement in survival rates for these infants. In contrast, the developing countries while shouldering approximately $90 \%$ of the world's burden of low birth weight infants only have around $10 \%$ of the world's resources for their care.

Low birth weight (LBW) related to intrauterine growth retardation (IUGR) is known to carry high morbidity and mortality, especially at term. In developing countries, it has been suggested that a substantial number of LBW infants also have IUGR. This may have a negative impact on the survival rates of LBW infants in these countries. These neonates are at higher risk of birth asphyxia, neonatal sepsis, hypothermia, hypoglycemia, hyperbilirubinemia (pathological), hypocalcemia, meconium aspiration syndrome(MAS), necrotizing enterocolitis, polycythemia, intraventricular hemorrhage, meningitis, apnea, bronchopulmonary dysplasia (BPD), patent ductus arteriosus(PDA), feeding difficulties, other congenital anomalies, etc. Many faces an increased risk of chronic diseases including a significant percentage of them suffer from protein-energy malnutrition and high blood
Pressure, non-insulin-dependent diabetes mellitus, infection, etc [2]. Adults born with LBW suffers from coronary heart disease and stroke in adulthood.

LBW also indicates malnutrition and ill health of the mother. There is a significant and strong correlation between maternal nutrition and the length of pregnancy and birth weight. High incidence of LBW indicates the deficient health status of the mother, inadequate antenatal care, and the need for improved care of the newborn babies. It has long been used as an important public health indicator.LBW is not a proxy for any one dimension of maternal or perinatal health outcomes. Globally, the indicator is a good summary measure of multifaceted public health problems that include long-term maternal malnutrition, ill health, hard work, and poor pregnancy health care. The smaller the baby, the more important it is to monitor his other growth in the weeks after birth. This is particularly important for infants at high risk of poor feeding and inadequate growth. Countries should, therefore, be encouraged to ensure accurate and reliable weighing of infants as close to birth as possible. Current Neonatal mortality rate (NMR) in India is 29 in 2013. Three fourth of neonatal deaths occur among low birth weight newborns. India Newborn Action Plan (INAP) was started on September 18th, 2014 with a goal of NMR less than 10 by 2030 [3].

Although technological advancements in perinatal and neonatal care have helped to improve the survival of low birth weight babies, a significant number of them remain with severe sequels such as malnutrition, recurrent infections, and neurodevelopmental handicaps. Hence the emphasis should be on intact survival. The majority of newborns with birth weight less than $1500 \mathrm{gm}$ survive without any sequel in developed countries, this improvement has not been seen on a global scale. The data from the developed countries can not readily be extrapolated to developing countries because of major differences in the availability of intensive care facilities, demographic and socioeconomic conditions.

Data on morbidity and mortality profile and long term neurodevelopmental outcome of low-birthweight babies from developing countries like India is scarce and is essential for planning and improvement of perinatal and neonatal services based on local needs. Hence the present study was taken up to evaluate the immediate complications, as well as physical growth and neurodevelopmental 
Outcome at 6 months, follow up of LBW babies admitted and treated in our SNCU.

\section{Materials and Methods}

Study Design: Cross-sectional observational study

Place: Sick Newborn Care Unit (SNCU) of Pediatrics ward of Bankura Sammilani

Medical College and Hospital (B.S.M.C.H)

Duration: Study period extended from 1st June 2016 to 31st May 2017.

Sample size: Here a total of 404 babies were included in the present study.

Formula used $[3.84 \times(p \times q)] / /^{2}$. Here $p=(28 \%)$ (incidence of LBW in India is $28 \%$ as per

UNICEF), $q=100-p, l=$ desired precision, here it is $5 \%[4]$.

Study population: Neonates in SNCU satisfying all inclusion criteria and none of the exclusion criteria enrolled in the study.

\section{Inclusion criteria}

- Birth Weight less than $2500 \mathrm{~g}$.

- The infant was less than 28 days.

- Parents/guardians had given written consent.

\section{Exclusion criteria}

- Birth weight more than $2500 \mathrm{~g}$.

- Birth weight less than $500 \mathrm{~g}$.

- An infant for more than 28 days.

- Parents did not give written consent.

Methods: The low birth weight newborn was observed immediately after birth till discharge and all the minute details of events in case of morbidity and or mortality were collected. A detailed examination was carried out in SNCU using a thermoneutral environment which includes birth weight, length, head and chest circumference. Weight was measured using an electronic weighing machine (accuracy $\pm 10 \mathrm{gm}$ ). Weight was put into OLSEN IE'S intrauterine growth chart to classify SGA and AGA. Recumbent length (Crown to heel length) was recorded with the help of an Infantometer. Gestational Age was calculated using New Modified Ballard Score to the neonates. The LBW neonates who were otherwise healthy no investigation was done. Diagnosis of various diseases was done on basis of clinical presentation
And available and affordable laboratory investigations. The criteria and definition of neonatal morbidities were based upon recommendations of the National Neonatology Forum of India [5].

Definitions used Respiratory distress syndrome was diagnosed based on the onset of respiratory distress within 6 hrs and characteristic radiological findings. Sepsis was diagnosed based on clinical features, positive septic screen, and positive blood cultures. Hypoglycaemia was defined as RBS < $40 \mathrm{mg} / \mathrm{dl}$. Necrotizing enterocolitis was diagnosed based on modified Bells staging criteria. BPD was diagnosed based on criteria of oxygen requirement at 36 weeks postmenstrual age for babies $<32$ weeks gestational age and for babies > 32 weeks, oxygen requirement at 56days postnatal age.USG was done on 3, 7, and 21 days to detect intraventricular hemorrhage. Discharged babies were followed up every week in the first month, at immunization visits, i.e. $6,10,14$ weeks and then at 6 months of age.

At follow up visits any medical complications were noted, anthropometric data were collected and neurodevelopmental assessment was done by using Trivandrum developmental screening Chart [6]. If any delay in the development was identified, mothers were counseled about the early stimulation of these babies. For growth monitoring WHO Z score charts were used for term babies and Fenton charts were used for preterm babies till 40 weeks of corrected gestation age and the WHO charts thereafter [7].

All Relevant data regarding mother's past and present obstetrics history was collected from the treatment files and antenatal records.

Statistical Methods: All data were collected, compiled, and subjected to statistical analysis with the help of SPSS software (version 20.0) and Medcalc (version 17.9.2). Microsoft word 2013 and Microsoft Excel 2013 were used to generate the tables, graphs, etc. Categorical variables were compared in two groups with the help of the Chisquare test. A p-value of $<.05$ was considered statistically significant for analysis at a $95 \%$ confidence interval.

Permission from IEC/IRB: Necessary permission for conducting the study and to publish the results observed were obtained from the Institutional Ethics Committee/ Institutional Review Board of this College. 


\section{Results}

Table-1: Distribution of study population according to birth weight.

\begin{tabular}{|l|l|}
\hline \multicolumn{1}{|c|}{ Birth weight $(\mathrm{gm})$} & \multicolumn{1}{c|}{ No of babies } \\
\hline$<1000$ & $38(9.4 \%)$ \\
\hline $1000-<1500$ & $134(33.2 \%)$ \\
\hline $1500-<2500$ & $232(57.4 \%)$ \\
\hline Total & $404(100 \%)$ \\
\hline
\end{tabular}

$\mathrm{X} 2$ value $=139.7 \mathrm{Df}=2 \mathrm{p}<.0001$

The total no of babies enrolled in the study were 404. Among them, 38(9.4\%)babies were weighing $<1000 \mathrm{gm}, 134(33.2 \%)$ babies were weighing 1000$<1500 \mathrm{gm}$ and rest232(57.4\%) babies were weighing between $1500-<2500 \mathrm{gm}$.

Table-2: Distribution of study population according to gestational age.

\begin{tabular}{|l|l|l|l|}
\hline \multirow{2}{*}{ Gestational age (weeks) } & \multicolumn{3}{|c|}{ Birth weight group } \\
\cline { 2 - 4 } & $1(n=38)$ & $2(n=134)$ & $3(n=232)$ \\
\hline 26 & $7(18.4 \%)$ & 0 & 0 \\
\hline 27 & $9(23.7 \%)$ & 0 & 0 \\
\hline 28 & $13(34.2 \%)$ & $1(0.7 \%)$ & 0 \\
\hline 30 & $8(21.1 \%)$ & $7(5.2 \%)$ & 0 \\
\hline 31 & $1(2.6 \%)$ & $37(27.6 \%)$ & 0 \\
\hline 32 & 0 & $28(20.9 \%)$ & 0 \\
\hline 33 & 0 & $41(30.6 \%)$ & $5(2.2 \%)$ \\
\hline 34 & 0 & $11(6.2 \%)$ & $25(10.8 \%)$ \\
\hline 35 & 0 & $1(0.7 \%)$ & $37(15.9 \%)$ \\
\hline 36 & 0 & $4(3 \%)$ & $45(19.4 \%)$ \\
\hline 37 & 0 & 0 & $36(15.5 \%)$ \\
\hline 38 & 0 & $3(2.2 \%)$ & $69(29.7 \%)$ \\
\hline 39 & 0 & $1(0.7 \%)$ & $14(6 \%)$ \\
\hline
\end{tabular}

From the above table, $316(78.2 \%)$ babies were preterm and 88 (21.8\%) babies were term IUGR. Among Birth weight, gr1 maximum babies were born at 28 weeks GA whereas in case of Birth weight gr 2 majorities of babies were born in between 30-32weeks and in case of Birth weight, gr 3 most of the babies were born in between 33-37 weeks.

Table-3: Distribution of study population according to presenting symptom.

\begin{tabular}{|l|l|l|l|}
\hline \multirow{2}{*}{ Symptoms } & \multicolumn{3}{|c|}{ Birth weight(gm) } \\
\cline { 2 - 4 } & $\begin{array}{l}<1000 \\
(\mathrm{n}=38)\end{array}$ & $\begin{array}{l}1000-<1500 \\
(\mathrm{n}=134)\end{array}$ & $\begin{array}{l}1500-<2500 \\
(\mathrm{n}=232)\end{array}$ \\
\hline Poor cry & $7(18.4 \%)$ & $31(23.1)$ & $55(23.7 \%)$ \\
\hline $\begin{array}{l}\text { Respiratory } \\
\text { Distress }\end{array}$ & $20(52.6 \%)$ & $50(37.3 \%)$ & $91(39.2 \%)$ \\
\hline
\end{tabular}

\begin{tabular}{|l|l|l|l|}
\hline Seizures & $5(13.2 \%)$ & $33(24.6 \%)$ & $44(19 \%)$ \\
\hline Poor feeding & $4(1.3 \%)$ & $60(44.8 \%)$ & $111(47.8 \%)$ \\
\hline Jaundice & $10(26.3 \%)$ & $32(23.9 \%)$ & $50(21.6 \%)$ \\
\hline Bleeding & 0 & 0 & $5(2.2 \%)$ \\
\hline Abdominal Distension & $2(5.3 \%)$ & $13(9.7 \%)$ & $15(6.5 \%)$ \\
\hline Apnea & $3(7.9 \%)$ & $8(6 \%)$ & $15(6.5 \%)$ \\
\hline
\end{tabular}

This table shows the presenting complaint in various LBW babies. Among those weighing less than $1000 \mathrm{gms}$, out of 38 babies $20(52.6 \%)$ babies had respiratory distress, $7(18.4 \%)$ had a poor cry, 5 (13.2\%) had seizures, $10(26.3 \%)$ had jaundice at presentation. Among those weighing between 1000$<1500 \mathrm{gm}$ out of 134 members, 60 (44.8\%) had poor feeding, $50(37.3 \%)$ presented with respiratory distress, and 31 (23.1\%) presented with a poor cry and 32 (23.9\%) presented with jaundice. Those weighing between $1500-<2500 \mathrm{gm}$ poor feeding formed the major proportions i.e.111 (47.8\%), 91 $(39.2 \%)$ presented with respiratory distress, 55 (23.7\%) had a poor cry, $50(21.6 \%)$ presented with jaundice and 44 (19\%) had seizures. Among 404 LBW babies, Poor feeding formed the predominant presenting complaints followed by respiratory distress and poor cry.

Table-4: Morbidity profile among low birth weight babies.

\begin{tabular}{|l|l|l|l|l|}
\hline \multirow{2}{*}{ Morbidity } & \multicolumn{3}{|c|}{ Birth weight group } & \multirow{2}{*}{ Total (n=404) } \\
\cline { 2 - 4 } & $1(\mathrm{n}=38)$ & $2(\mathrm{n}=134)$ & $3(\mathrm{n}=232)$ & \\
\hline Hypoglycemia & $12(31.6 \%)$ & $35(26.1 \%)$ & $24(10.3 \%)$ & $71(17.6 \%)$ \\
\hline Sepsis & $13(34.2 \%)$ & $53(39.6 \%)$ & $127(54.7 \%)$ & $193(47.8 \%)$ \\
\hline Hyperbilirubinemia & $19(50 \%)$ & $40(29.9 \%)$ & $70(30.2 \%)$ & $129(31.9 \%)$ \\
\hline RDS & $15(39.5 \%)$ & $29(21.6 \%)$ & $9(3.9 \%)$ & $53(13.1 \%)$ \\
\hline HIE & $8(21.1 \%)$ & $30(22.4 \%)$ & $81(34.9 \%)$ & $119(29.5 \%)$ \\
\hline NEC & $6(15.8 \%)$ & $13(9.7 \%)$ & $4(1.7 \%)$ & $23(5.7 \%)$ \\
\hline PDA & $3(7.9 \%)$ & $5(3.7 \%)$ & $2(0.8 \%)$ & $10(2.5 \%)$ \\
\hline Apnea & $13(34.2 \%)$ & $49(36.6 \%)$ & $19(8.2 \%)$ & $81(20 \%)$ \\
\hline Seizures & 0 & $2(1.5 \%)$ & $3(1.3 \%)$ & $5(1.3 \%)$ \\
\hline HDN & 0 & $1(0.7 \%)$ & $5(2.2 \%)$ & $6(1.5 \%)$ \\
\hline IVH & $3(7.9 \%)$ & $2(1.5 \%)$ & 0 & $5(1.2 \%)$ \\
\hline BPD & $1(2.6 \%)$ & $2(1.5 \%)$ & 0 & $3(0.7 \%)$ \\
\hline Congenital anomalies & $2(5.3 \%)$ & $2(1.5 \%)$ & $20(8.6 \%)$ & $24(5.9 \%)$ \\
\hline
\end{tabular}

Major morbidities included Hypoglycemia (17.6\% suffered from hypoglycaemia, and this was statistically significant $(p<.001)$, Sepsis $[193$ $(47.8 \%)$ LBW babies had suffered from sepsis],Hyperbilirubinemia[Total 129 (31.9\%) newborn had suffered from Hyperbilirubinemia], RDS [53 (13.1\%) infant had suffered from RDS ], HIE [119 (29.5\%) LBW newborn had suffered from HIE], NEC [23(5.7\%) babies had suffered from NEC], PDA [10 (2.5\%) newborn were detected PDA] 
Apnea $[81(20 \%)$ babies were apneic], Seizure Disorder [only $5(1.2 \%)$ newborn had suffered from Seizure disorder], HDN [6 (1.5\%) LBW babies suffered from HDN], IVH [ $5(1.25 \%)]$, BPD [3 $(0.7 \%)$ babies suffered from BPD], Congenital Anomalies $[24(5.9 \%)$ babies were found to have born with different congenital anomalies].

Among all of this Hypoglycemia, RDS, HIE, Sepsis, Hyperbilirubinemia, NEC, PDA, Apnea, IVH, and Congenital anomalies were significantly associated with LBW babies $(p<.05)$.

Table-5: Distribution of study population according to the outcome.

\begin{tabular}{|l|l|l|l|l|}
\hline \multirow{2}{*}{ Outcome } & \multicolumn{3}{|c|}{ Birth weight group } & \multirow{2}{*}{ Total $(\mathrm{n}=404)$} \\
\cline { 2 - 4 } & $1(\mathrm{n}=38)$ & $2(\mathrm{n}=134)$ & $3(\mathrm{n}=232)$ & \\
\hline Death & $25(65.8 \%)$ & $44(32.8 \%)$ & $26(11.2 \%)$ & $95(23.5 \%)$ \\
\hline Discharged & $10(26.3 \%)$ & $88(65.7 \%)$ & $204(87.9 \%)$ & $302(74.8 \%)$ \\
\hline Referred & $3(7.9 \%)$ & $2(1.5 \%)$ & $2(0.9 \%)$ & $7(1.7 \%)$ \\
\hline
\end{tabular}

In the present study mortality rate was $23.5 \%$ (95, $n=404)$.

Among ELBW babies i.e. Birth weight group 1, 25 i.e $65.8 \%(n=38)$ infants had died and $10(26.3 \%$, $\mathrm{n}=38$ ) babies were discharged successfully and 3 $(7.9 \%, \mathrm{n}=38)$ were referred to higher centre.

Among VLBW infants i.e. Birth weight group 2, 44 $(32.8 \%, \mathrm{n}=134)$ newborn had died, $88(65.7 \%$, $\mathrm{n}=134)$ were discharged successfully and $2(1.5 \%$, $\mathrm{n}=134$ ) were referred tohigher centre for further management.

Among babies weighing between $1.5-<2.5 \mathrm{~kg}$, i.e. Birth weight group 3, $26(11.2 \%, \mathrm{n}=232)$ had died, $204(87.9 \%, n=232)$ were discharged and $7(1.7 \%$, $\mathrm{n}=232$ ) were referred to higher centre for further management.

Table-6: Cause of death among LBW neonates.

\begin{tabular}{|l|l|l|l|}
\hline \multirow{2}{*}{ Cause of death } & \multicolumn{3}{|c|}{ Birth weight group } \\
\cline { 2 - 4 } & $1(\mathrm{n}=25)$ & $2(\mathrm{n}=44)$ & $3(\mathrm{n}=26)$ \\
\hline SEPSIS & $6(24 \%)$ & $22(51 \%)$ & $16(63 \%)$ \\
\hline RDS & $8(32 \%)$ & $10(23 \%)$ & 0 \\
\hline HIE & $3(12 \%)$ & $5(12 \%)$ & $7(28 \%)$ \\
\hline NEC & $4(16 \%)$ & $2(5 \%)$ & 0 \\
\hline APNEA & $3(12 \%)$ & $3(7 \%)$ & $1(4 \%)$ \\
\hline IVH & $1(4 \%)$ & $1(2 \%)$ & 0 \\
\hline PDA & 0 & $1(2 \%)$ & 0 \\
\hline CongenitalAnomalies & 0 & 0 & $2(5 \%)$ \\
\hline
\end{tabular}

RDS (32\%, $n=25)$ was the commonest cause of ELBW babies' mortality, followed by SEPSIS (24\%), NEC (16\%), APNEA (12\%), HIE (12\%) and IVH
(4\%), sepsis $(51 \%)$ followed by RDS $(23 \%)$, HIE $(12 \%)$, APNEA ( $7 \%)$ were a most common cause of death among Birth weight group 2 i.e. between $1000-<1500 \mathrm{gm}$, and the major cause of death among Birth weight group3 i.e. between 1500$<2500 \mathrm{gm}$ were sepsis (63\%), HIE (28\%), congenital anomalies (5\%) and apnea (4\%).

Table-7: Follow up profile among discharged babies.

\begin{tabular}{|l|l|l|l|l|}
\hline \multirow{2}{*}{ Follow up profile } & \multicolumn{3}{|c|}{ Birth weight group } & \multirow{2}{*}{ Total } \\
\cline { 2 - 4 } & 1 & 2 & 3 & \\
\hline $\begin{array}{l}\text { No of babies enrolled for } \\
\text { follow up }\end{array}$ & $\begin{array}{l}3.4 \%) \\
(3.48(29.4 \%)\end{array}$ & $201(67.2 \%)$ & $299(100 \%)$ \\
\hline $\begin{array}{l}\text { Babies completed follow } \\
\text { up }\end{array}$ & $\begin{array}{l}7(70 \%, \\
n=10)\end{array}$ & $\begin{array}{l}68(77.3 \%, \\
n=88)\end{array}$ & $\begin{array}{l}125(62.2 \%, \\
n=201)\end{array}$ & $\begin{array}{l}200(66.9 \%, \\
n=299)\end{array}$ \\
\hline $\begin{array}{l}\text { Babies required recurrent } \\
\text { hospitalisation }\end{array}$ & $\begin{array}{l}47(69.1 \%, 1 \%, \\
n=7)\end{array}$ & $\begin{array}{l}33(26.4 \%, \\
n=68)\end{array}$ & $\begin{array}{l}84(42 \%, \\
n=200)\end{array}$ \\
\hline
\end{tabular}

A total of $200(66.9 \%, n=299)$ babies had completed their follow up and a total of $84(42 \%$, $\mathrm{n}=200$ ) babies required recurrent hospitalization due to various causes.

Table-8: Developmental outcome of follow up babies.

\begin{tabular}{|l|l|l|l|l|}
\hline \multirow{2}{*}{$\begin{array}{c}\text { Developmental } \\
\text { outcome }\end{array}$} & \multicolumn{3}{|c|}{ Birth weight group } & \multirow{2}{*}{$\begin{array}{c}\text { Total } \\
(\mathrm{n}=200)\end{array}$} \\
\cline { 2 - 4 } & $1(\mathrm{n}=7)$ & $2(68)$ & $3(\mathrm{n}=125)$ & \multicolumn{1}{|c|}{$62(31 \%)$} \\
\hline Weight/length<2SD & 5 & 18 & 39 & $62 \%)$ \\
& $(71.4 \%)$ & $(26.5 \%)$ & $(31.2 \%)$ & \\
\hline Developmental delay & 5 & 14 & 21 & $40(20 \%)$ \\
& $(71.4 \%)$ & $(20.6 \%)$ & $(16.8 \%)$ & \\
\hline HC<3rd percentile & 5 & 13 & 24 & $42(21 \%)$ \\
& $(71.4 \%)$ & $(19.1 \%)$ & $(19.2 \%)$ & \\
\hline
\end{tabular}

The present study showed $62(31 \%, \mathrm{n}=200)$ babies had Weight/length $\angle 2 S D$ and among them 5 $(71.4 \%, \mathrm{n}=7)$ were Birth weight group 1,18 $(26.5 \%, n=68)$ were Birth weight group 2, 39 $(31.2 \%, \mathrm{n}=125)$ were Birth weight group 3 .

The above table showed $40(20 \%, n=200)$ babies had suffered from developmental delay, amongst them $5(71.4 \%, \mathrm{n}=7)$ were Birth weight group 1,14 $(20.6 \%, n=68)$ were Birth weight group 2 and 21 $(16.8 \%, \mathrm{n}=125)$ were Birth weight group 3.

Again $42(21 \%, \mathrm{n}=200)$ babies had developed $\mathrm{HC}<3$ rd percentile, among them $5(71.4 \%, \mathrm{n}=7)$ were Birth weight group 1, $13(19.1 \%, \mathrm{n}=68)$ were Birth weight group 2 and $24(19.2 \%, n=125)$ were Birth weight group 3 . 


\section{Discussion}

The study variables are discussed here as per the result and compared with similar studies. The total no of babies enrolled in the study were 404 . Out of 404 babies, 38 (9.4\%) babies were ELBW i.e. Birth weight group1, $134(33.2 \%)$ babies were weighing between $1000-<1500 \mathrm{gm}$ i.e. Birth weight group 2 and the rest $232(57.4 \%)$ babies weighed between $1.5 \mathrm{~kg}$ to $<2.5 \mathrm{~kg}$ i.e. Birth weight group 3 . Incidence of ELBW $(<1000 \mathrm{gm})$ babies was relatively high in the current study $(9.4 \%)$ which is more when compared to the study of Emel Altuncu et al $(3.3 \%)$ and Kayastha et al $(4.1 \%)$ depicting that the burden of ELBW was relatively high in the current study causing more burden of morbidity and mortality $[8,9]$. Babies' weighing between 1000$<1500 \mathrm{gm}$ incidence was also relatively high in the current study i.e., (33.2\%) when compared to Emel Altuncu et al $(10.7 \%)$ and Kayastha et al $(8.7 \%)$ $[8,9]$. The babies weighed between $1.5-<2.5 \mathrm{~kg}$ is $57.4 \%$ which is lower when compared to $\mathrm{D}$. Manikyamba et al (65.56\%) [10].

$316(78.2 \%)$ babies were preterm and $88(21.8 \%)$ babies were term IUGR babies and it is statistically significant $(p<.0001)$ which is similar to Agarwal $K$ et al, where the prevalence of LBW among mothers having gestational age less than 37 weeks at the time of delivery was $76.5 \%$ whereas $31.4 \%$ mothers had gestational age at the time of delivery 37 weeks and above [11].

The problem of extreme prematurity i.e. less than 28 weeks of gestational age was also very high in the current study which is comparable with Were FN et al i.e. ( $7.4 \%$ vs. $9 \%)$, which is less in the Kayastha et al $(3 \%)[9,12]$. Those born between 29 to 32 weeks were in the order of $31.2 \%, 16.5 \%$, and $29 \%$ in the Present study, the study by Kayastha et al and Were $\mathrm{FN}$ et al respectively $[9,12]$.

Presenting Symptoms: In the present study, presenting symptoms was not statistically significant. No such data were available in other studies.

Hypoglycemia: In the present study total of 71 babies i.e. $17.6 \%$ had suffered from hypoglycemia. Manikyamba $D$ et al. also found hypoglycemia in $15 \%$ LBW newborn [10].

Sepsis: In the present study there was a significant association between sepsis and LBW. 193 (47.8\%),
Makhoul et al found a strong association of sepsis with prematurity and low birth weight [13].

NH: A total of 129 (31.9\%) newborns had suffered from Hyperbilirubinemia. Manikyamba $D$ et al [10] $42 \%$ of LBW babies suffered from Hyperbilirubinemia. The higher incidence of NNH in preterm is well documented by Anil Narang et al, Vales et al and Venkataseshan et al [14].

RDS: $53(13.1 \%)$ infants suffered from RDS Caner et al indicated the incidence of RDS in $40.6 \%$ out of613 premature infants who were admitted to the neonatal intensive care unit [15]. RDS was also shown in $23 \%$ of neonates admitted to the NICU with gestational age $>28$ weeks by Arit et al [16]. The reasons for these differences in the epidemiology may relate to differences in the categorized gestational age of the participant.

HIE: $119(29.5 \%)$ LBW newborn had suffered from HIE Fetzhardinge et al and Srivastava JR et al have reported that the incidence of hypoxic-ischemic encephalopathy was $30 \%$ and $29 \%$ respectively $[17,18]$.

NEC: In this study, NEC was more common between $500-1500 \mathrm{gm}$ weighing babies. A similar result was obtained by Gregory et al [19].

PDA: In the present study PDA was significantly associated with LBW $(p<.018)$. Among $10(2.5 \%)$ newborn babies who were detected PDA, 3 (7.9\%) were ELBW,5 (3.7\%) Birth weight group 2 and 2 $(0.9 \%)$ were weighing among $1.5-<2.5 \mathrm{~kg}$. Studies by Van Overmeire B et al, Fanaroff AA et al. had reported an incidence of $15-40 \%$ in very low birth weight infants $(<1500 \mathrm{~g})$ whereas in premature extremely low birth weight infants (<28weeks; < $1000 \mathrm{~g}$ ) it's as high as $50-65 \%[20,21]$. The low incidence may be due to a lack of Echocardiography facility in the SNCU. However, the current study correlates with what was found Manikyamba $D$ et al [10].

APNEA: In the present study apnea seemed to be one of the most important causes of morbidity. 81 $(20 \%)$ babies were apneic. Manikyamba D et al also had found apnea in 18\% LBW newborn [10].

Seizure Disorder: The current study showed that only $5(1.2 \%)$ newborn babies had suffered from a Seizure disorder, This study is not statistically significant $(p=0.75)$. A study by Dr.G.V. Rama Devi et al. showed $1.7 \%$ of LBW babies had suffered from seizures [22]. More studies are required in this 
Regard.

HDN: In the present study $6(1.5 \%)$ LBW babies had suffered from HDN.This is not statistically significant. $(p=0.4)$. A study by Dr. G.V. Rama Devi et al. showed $1.2 \%$ of LBW babies had suffered from HDN. More studies are required in this regard [22].

IVH: In the present study IVH was significantly associated with LBW $(p<0.0002)$. Total no IVH it was found that $5(1.2 \%)$ among them 3 were ELBW babies and 2 were Birth weight group, 2 babies. Manikyamba $D$ et al. had found $1 \%$ of cases of IVH [10]. However, Debbarma R et al and Dincosy MY et al had found different results $[23,24]$. Differences may be due to different patient profiles. More studies are required in this field.

BPD: In the present study $3(0.7 \%)$ babies had suffered from BPD, 1 was ELBW, and 2 were Birthweight group2 and this finding was not significant. More studies are required in this regard to come to a conclusion.

CA: In the present study $24(5.9 \%)$ babies were found to have been born with different congenital anomalies. Emel Altuncu et al had found congenital anomalies in $6.7 \%$ LBW infants [8]. However, that study was performed in the maternity ward. So, more studies are required in this field.

Outcome: In the present study mortality rate was $23.5 \%$ (95). Manikyamba $D$ et al had found mortality of LBW was $24 \%$ which was close to the present study $23.5 \%(95, \mathrm{n}=404)$ [10].

Dr. G.V. Rama Devi et al had shown in their study that mortality of LBW was $32.9 \%$ [22].

Acharya et al had found mortality among VLBW babies was $25 \%$ which is less than the present study but the mortality rate of ELBW was $69.7 \%$ which was more than that of the present study [25], babies were more than Poudel et al [26]. There is a wide variety of survival rates reported in various studies $[27,28]$. Among ELBW babies major three causes of death were RDS (32\%), Sepsis (24\%), and NEC (16\%). Three major causes of death of babies weighing between $1000-<1500 \mathrm{gm}$ i.e. Birth weight group 2 were Sepsis (50\%), RDS (23\%), and HIE $(11 \%)$ similar to study by Vinayak K. Patki et al [28].

The major cause of death among birth weight 1.5$<2.5 \mathrm{~kg}$ were Sepsis $(63 \%)$, HIE (28\%).
Developmental Outcome: In the present study at 6 months corrected age $69 \%$ of babies showed good to catch up growth. Bavadekar et al reported catch up growth in only $20 \%$ of LBW babies [29]. Modi et al reported significantly lower $Z$ scores of weight for length and head circumference [30]. In the present study developmental delay, the major cause of concern in the long-term care of surviving LBW babies all over the world was noted $20 \%$ and $20.6 \%$ in LBW and VLBWbabies respectively. Modi et al reported lower mean DQ by 6 points in the VLBW cohort and Mukopadhaya et al observed lower mean mental and motor DQ $(<70)$ in $17 \%$ and $26 \%$ of VLBW babies $[30,31]$.

\section{Conclusion}

'Low birth weight babies' remains an important health problem since very old times and poses a major threat to neonatal survival. It is often stated that more the birth weight more developed the nation. Neonatal morbidity and consequent mortality are mostly related to the incidence of low birth weight neonates.' Low birth weight babies' imposes a serious burden to the entire neonatal care service system, needing more hospital stay, management as a whole, and in brief more resource mobilization. In our series mortality among low birth weight babies was high (23.5\%). Immediate complications and complications after 6 months follow up were also on the higher side. To reduce the incidence of LBW babies and mortality, the best way is to improve maternal health, nutrition, proper antenatal care. Major morbidity factors were Sepsis, RDS, Birth Asphyxia, and Apnea.

Proper asepsis procedure, judicious use of antibiotics, timely intervention like CPAP, etc. can reduce the mortality profile among LBW infants. The neuro-developmental delay was seen among $20 \%$ of babies and poor catch up growth was seen around $31 \%$ infants after 6 months of follow up. Proper counseling while discharge regarding feeding, warmth care, asepsis, danger sign and need for follow up plays a pivotal role in the neurodevelopmental outcome. 99 babies (around one third) were lost during follow up.

Tracking of discharged babies by Health workers can improve the outcome. Regular and timely follow up and early identification of risk factors, early stimulation, early identification of growth faltering can improve the overall outcome. Though with improved neonatal care services the mortality rate 
Has been reduced significantly; it may give rise to a population of infants and children; and even adults who may have to live with serious handicaps for the rest of their life.

After everything being said and done, low birth weight is better to be prevented than treated. But the fact remains that preventing the occurrence of low birth weight is only feasible by elevation of maternal health care services and that part, surely and scientifically; not to prophesize; can be done by elevating the socio-economic standard of a country.

\section{Author's contributions}

Dr. Sudipta Bandyopadhyay performed the entire work. He collected data from all the cases and compiled them. He performed the statistical analysis and drafted final manuscripts.

Dr. Abhay Charan Pal conceived the idea and contemplated the study plan. He revised the manuscripts by adding many intellectual contents.

Dr. Snehansu Chakraborti gave necessary guidance during the study. He also added some intellectual content.

\section{Reference}

01. WHO. International statistical classification of diseases and related health problems. 10th Revision- Geneva; World Health Organization. 1992;2;151-152.

[Crossref]

02. United Nations Administrative Committee on Coordination/Sub-Committee on Nutrition(ACC/SCN). Fourth Report on the World Nutrition Situation. Geneva- ACC/SCN incollaboration with International Food Policy Research Institute (IFPRI). 2000.

[Crossref]

03. India Newborn Action Plan. Ministry of health and family welfare. Govt of India. 2014.

[Crossref]

04. UNICEF's. The State of the World's Children. UNICEF. 2014.

[Crossref]

05. Nair MK, George B, Philip E, Lekshmi MA, Haran JC, Sathy N. Trivandrum Developmental Screening Chart. Indian Pediatr. 1991;28(8)869872.

[Crossref]
06. NNF. Evidence Based Clinical Practice Guidelines. National Neonatology Forum India. 2010.

[Crossref]

07. Fenton TR. Preterm Growth Chart 2003 calculations. Member Shaw. 2003.

Available from:

chart/Fenton_Growth_Chart_calculations.xls

[Article:http://members.Shaw.Ca/growth][Crossref]

08. Altuncu E, Kavuncuoğlu S, Özdemir Gökmirza P, Albayrak Z, Arduç A. The incidence of low birth weight in 5000 liveborn infants and the etiology of fetal risk factors. Marmara Med J. 2006;19(2)46-51.

[Crossref]

09. Kayastha S, Tuladhar H. Study of low birth weight babies in Nepal MedicalCollege. Nepal Med Coll J- NMCJ. 2007;2008;9(4)266-269.

[Crossref]

10. D Manikyamba, N Madhavi. Morbidity and Mortality Profile of LBW Babies and Their Growth and Neurodevelopment Outcome at 1 yearNICU, Government General Hospital, Kakinada. Sch J App Med Sci. 2015;3(4B)1721-1725. [Crossref]

11. Agarwal K, Agarwal A, Agarwal VK, Agalwal P, Chaudhary $V$. Prevalance and determinants of low birth weight among institutional deliveries. Ann Nigerian Med. 2011;5(2)48-52.

[Crossref]

12. Van Overmeire $B$, Van de Broek $H$, Van Laer $P$, Weyler J, Vanhaesebrouck P. Early versus late indomethacin treatment for patent ductus arteriosus inpremature infants with respiratory distress syndrome. J Pediatr. 2001;138(2)205211.

[Crossref]

13. Makhoul IR, Sujov $P$, Smolkin T, Lusky A, Reichman B. Epidemiological, clinical and microbiological characteristics of late onset sepsis among Very low birth weight infants in Israel. Pediatr. 2002;109(1)34-39.

[Crossref]

14. Caner I, Tekgunduz KS, Temuroglu A, Demirelli Y, Kara M. Evaluation of Premature Infants Hospitalized in Neonatal Intensive Care Unit between 2010-2012. Eurasian J Med. $2015 ; 47(1) 13$.

[Crossref] 
15. Narang A, Kumar P, Kumar R. Neonatal jaundice in Very low birth weight babies. Indian J Pediatr. 2001;68(41)307-315.

[Crossref]

16. Were FN, Mukhwana BO, Musoke RN. Neonatal survival of infants less than 2000 grams born at Kenyatta National Hospital. East African Med J. 2002;79(2)77-79.

[Crossref]

17. Parkash A, Haider N, Khoso ZA, Shaikh AS. Frequency, causes and outcome of neonates with respiratory distress admitted to Neonatal Intensive Care Unit, National Institute of Child Health, Karachi. J Pak Med Assoc. 2015;65(7)771-775.

[Crossref]

18. Fitzhardinge PM. Early growth and development in low-birthweight infants following treatment in an intensive care nursery. Pediatr. $1975 ; 56(2) 162-172$.

[Crossref]

19. Bhalla JN, Bhalla M, Srivastava JR. Effects of intrauterine growth and gestational maturity on the morbidity and mortality pattern of babies. Requiring special case, Indian Pediatr. $1979 ; 16(1) ; 41$.

[Crossref]

20. Shankaran $S$, Fanaroff $A A$, Wright $L L$, Stevenson $\mathrm{DL}$, Donovan FF, Ehrenkranz RA, et al. Risk factors for early death among extremely low birth weight infants. Am J Obstet Gynaecol. 2002;186(4)796- 802.

[Crossref:Crossref]

21. Fanaroff $A A$, Stoll $B J$, Wright $L L$, Carlo $W A$, Ehrenkranz RA, Stark $A R$, et al. Trends in neonatal morbidity and mortality for very low birth weight infants. Am J Obstet Gynecol. 2007; 196(1)147e1.

[Crossref]

22. Devi GR, Rao KR, Reddy VV. Morbidity and Mortality of Low Birth weight Newborns Admitted in SNCU/NICU in A Tertiary Care Hospital. J Dent Med Sci. 2017;16(1)28-32.

[Crossref]

23. Debbarma $R$, De $A$, Debbarma $S$. Incidence of intracranial haemorrhage in low-birth weight infants and its outcome- a hospital based prospective study. Int J Res Med Sci. 2016;4(10)4279-4285.

[Crossref]
24. Dincsoy MY, Siddiq F, Kim YM. Intracranial hemorrhage in hypothermic Low birth weight neonates. Child Nan Cyst. 1990;6(5)245-248.

[Crossref]

25. Acharya N, Mishra P, Shrestha N, Gupta V. Immediate Outcome of VIbw And Elbw Babies in a Tertiary Care Center of Nepal. J Nepalgunj Med Coll. 2014;12(1)32-34.

[Crossref]

26. Poudel $P$, Budhathoki $S$, Shrivastava MK. Maternal risk factors and morbidity pattern of very low birth weight infants- a NICU based study at eastern Nepal. J Nepal Pediatr Soc. 2009;29(2)59-66.

[Crossref]

27. Patki VK, Antin JV. Maternal antenatal profile and immediate neonatal outcome in very low birth weight babies. Int J Med Pediatr Oncol. 2017;3(2)64-70.

[Crossref]

28. Bavadekar AR, Vaidya UV, Bhave SA, Pandit AN. Catch up growth and its determinants in low birth weight babies- A study using $Z$ scores. Indian Pediatr. $1994 ; 31 ; 1483-1490$.

[Crossref]

29. Gregory KE. Clinical predictors of necrotizing enterocolitis in premature infants. Nurs Res. 2008;57(4)260-270.

[Crossref]

30. Modi M, Saluja S, Kler N, Batra A, Kaur A, Garg $P$, Suman P. Growth and neurodevelopment outcome of VLBW infants at 1-year corrected age at 2 years. Indian $\mathrm{J}$ Pediatrics. 2013;50(6)573-467.

[Crossref]

31. Mukhopadhaya K, Malhi P, Mahajan R, Narang A. Neurodevelopmental and behavioural outcome of VLBW babies at corrected age of 2 years. Indian J Pediatrics. 2010;77(9)963-967. [Crossref] 